\title{
Phonological Facilitation in Picture-Word Interference Experiments: Effects of Stimulus Onset Asynchrony and Types of Interfering Stimuli
}

\author{
A. S. Meyer and H. Schriefers \\ Max-Planck Institute for Psycholinguistics \\ Nijmegen, The Netherlands
}

\begin{abstract}
Subjects named pictures while hearing distractor words that shared word-initial or word-final segments with the picture names or were unrelated to the picture names. The relative timing of distractor and picture presentation was varied. Compared with unrelated distractors, both types of related distractors facilitated picture naming under certain timing conditions. Begin-related distractors facilitated the naming responses if the shared segments began $150 \mathrm{~ms}$ before, at, or $150 \mathrm{~ms}$ after picture onset. By contrast, end-related distractors only facilitated the responses if the shared segments began at or $150 \mathrm{~ms}$ after picture onset. The results suggest that the phonological encoding of the beginning of a word is initiated before the encoding of its end.
\end{abstract}

A central concern of current research on language production is to determine which planning processes are carried out in parallel and which are executed in sequence. For example, one important question is the time course of the access to meaning and form of a word. Whether these two processes overlap in time or represent strictly successive stages and whether feedback is possible from word forms to meanings are highly controversial issues (e.g., Dell \& Reich, 1981; Garrett, 1975, 1976, 1988; Levelt, 1989; Levelt et al., 1991; Martin, Weisberg, \& Saffran, 1989; Schriefers, Meyer, \& Levelt, 1990). At any rate, there is general agreement that access to a word's meaning is at least initiated before access to its form and that the choice of a word form is largely determined by the selected word meaning.

Whereas most past research on the time course of lexical access has concerned the relative timing of accessing meaning and phonological form of a word, the present experiments investigate the timing of the processes inside the phonological component. The retrieval of the phonological form of a word, given its meaning, will be called phonological encoding. An important result of analyses of speech errors is that word forms cannot be retrieved from the mental lexicon as entities but must be constructed out of smaller parts (see, e.g., Fromkin, 1971, 1973; Shattuck-Hufnagel, 1979, 1983). This follows from the observation that speakers often make sound errors (i.e., produce utterances that deviate from the intended ones in one or more sounds not corresponding to complete morphemes). If word forms were retrieved as entities, such

We thank J. Nagengast for writing the software controlling the experiments; G. Desserjer and H. Franssen for their help in preparing the stimuli, running the experiments, and analyzing the data; I. Tarim for preparing the figures; and W. J. M. Levelt, S. Lupker, and two anonymous reviewers for their helpful comments on an earlier version of the article.

H. Schriefers is now at the Free University, Berlin.

Correspondence concerning this article should be addressed to A. S. Meyer, Max-Planck Institute for Psycholinguistics, Postbus 310, NL-6500 AH Nijmegen, The Netherlands. errors could not arise. Thus, sound errors reveal that word forms must be made up of sublexical units. However, they do not provide direct evidence about the time course of this process.

In most sound errors, single segments or sequences of two adjacent segments are replaced by incorrect ones (see Examples 1 and 2 below). By contrast, errors involving complete syllables (see Example 3) or single phonological features (see Example 4) are relatively rare (e.g., Fromkin, 1971; MacKay, 1970; Nooteboom, 1969; Shattuck-Hufnagel, 1979, 1983). This suggests that the sublexical units out of which phonological forms are created are phonological segments and perhaps certain segment sequences:

(1) a phonological fool (a phonological rule)

(2) fleaky squoor (squeaky floor)

(3) tremenly (tremendously)

(4) glear plue sky (clear blue sky)

(5) craperies cleaned (draperies cleaned)

(based on Fromkin's, 1973, Appendix)

Although syllables are not common as error units, there is evidence that the syllabic structure of words is included in the phonological representations created in language production. First, the replaced sounds and sound sequences tend to correspond to complete syllable constituents of the intended words (MacKay, 1970, 1972; Shattuck-Hufnagel, 1983; Stemberger, 1983). Errors in which only one segment of a complex constituent is incorrect (see Example 5) are relatively rare. Second, in movement errors, segments tend to migrate from their intended positions to corresponding positions in new syllables rather than to different positions (Boomer \& Laver, 1968; Fromkin, 1971; Shattuck-Hufnagel, 1979). For instance, segments that were meant to appear in onset positions tend to take new onset positions rather than nucleus or coda positions (see Examples 1 and 2).

On the basis of this and related evidence (see, e.g., Browman, 1978; Brown \& McNeill, 1966; Treiman, 1983, 1984, 1986), most models of phonological encoding assume that 
the entries in the mental lexicon include information about the words' segments and about their syllabic structure (see, e.g., Dell, 1986; Shattuck-Hufnagel, 1979, 1983). Syllables are often viewed as frames of slots. The slots correspond to syllable constituents. Instead of syllable frames, some models assume word frames capturing the number and types of segments (vowels or consonants) that words include and their linear order (see, e.g., Dell, 1988; Stemberger, 1990). Phonological encoding is usually assumed to involve retrieval of phonological segments, creation of a frame, and insertion of the segments into the slots of the frame (but see Levelt, 1989, for a more complex model of phonological encoding).

Current models of phonological encoding differ in their assumptions about the time course of phonological encoding. In Dell's (1986) spreading activation model, all segments of a given syllable become highly activated at the same time and can be inserted into the slots of the syllable frame in any order. Segments belonging to different syllables reach their activation maximum successively, according to their order in the word, and are inserted into syllable frames in that order. By contrast, in Shattuck-Hufnagel's $(1979,1983)$ model, all slots of a word, those within a given syllable as well as those of successive syllables, must be filled in a particular order, proceeding from the onset of the word to its end. In a later version of the model (Shattuck-Hufnagel, 1987), word onsets are encoded last. Thus, according to all models, words are encoded in a number of ordered processing steps, but in Dell's (1986) model the parts of a word that are encoded in successive steps are syllables, whereas in Shattuck-Hufnagel's (1979, 1983 , 1987) model they are syllable constituents. When the models were designed, no empirical evidence on the time course of phonological encoding was available. Dell's and Shattuck-Hufnagel's assumptions concerning this issue are merely based on considerations of plausibility.

Meyer $(1990,1991)$ carried out a series of experiments testing which of the two proposals, if either, is correct. A task was used in which the subjects on each test trial said one out of three or five response words. In so-called homogeneous test blocks, the response words were phonologically related in specific ways, sharing, for example, the first segment or syllable. In heterogeneous blocks the response words were unrelated in form. When the response words in the homogeneous condition shared word-initial segments, utterance onset latencies were shorter in this than in the heterogeneous condition. By contrast, when the response words in the homogeneous condition shared word-internal or word-final segments but not the word onset, no facilitatory effect was obtained. These findings support the assumption that different parts of word forms are created in a particular order, namely, proceeding from the beginning of the word to its end. The strength of the facilitatory effect increased with the number of successive syllable onsets and rhymes the words had in common, which suggests that in each processing step one onset or rhyme was encoded. This supports Shattuck-Hufnagel's proposal that the units that are encoded in succession are syllable constituents, rather than Dell's proposal that they are complete syllables. It should be noted that a modified version of Dell's (1988) model allows for the possibility of serial activation of segments within syllables.
Though Meyer's $(1990,1991)$ results strongly suggest that word forms are assembled in a number of ordered processing steps, the results are open to alternative interpretations. In particular, it can be argued that they merely show which types of information subjects can use to prepare for the production of response words and which types they cannot use. It is possible that these differences are not directly related to the order of phonological encoding of words but to other factors, such as the order of articulation. For example, when all response words of a given test block began with the same syllable, the subjects could prepare themselves by keeping their speech organs in an optimal starting position for the utterance of that syllable between trials. Such articulatory preparation was not possible when the response words of a block shared the second but not the first syllable. As several accounts are possible for Meyer's results, it seemed important to test the time course of phonological encoding again, using a different paradigm.

In the experiments reported below, a picture-word interference paradigm was used, which is related to the classical Stroop paradigm (Stroop, 1935; Virzi \& Egeth, 1985; see also Cowan, 1989a, 1989b, Cowan \& Barron, 1987, Miles \& Jones, 1989, Miles, Madden, \& Jones, 1989, and Schriefers \& Meyer, 1990 , for studies using cross-modal versions of the Stroop paradigm). In the present experiments, the subjects were presented with pictures of common objects (called targets hereinafter), which they had to name as quickly as possible. Naming latency was the main dependent variable. The target names were mono- or disyllabic nouns. In one condition (silence) the subjects only saw the pictures; in the remaining conditions, they also heard words (interfering stimuli [ISs]).

For each target there were two phonologically related ISs and two unrelated ones. The related ISs for disyllabic targets shared either the first or the second syllable with the targets. For example, the two related ISs for the target hamer (['ha:mor], hammer) were havik (['ha:.vIk], hawk) and zomer (['zo:.mer], summer). The related ISs for monosyllabic targets shared either onset and nucleus or nucleus and coda with the targets. For example, the two related ISs for the target veer ([ve:r], feather) were veen ([ve:n], peat) and peer ([pe:r], pear). The two types of ISs are called begin-related and end-related ISs, respectively.

We had included the begin-related, unrelated, and silence conditions in earlier picture-word interference experiments (Schriefers et al., 1990). In those experiments we also varied the stimulus onset asynchrony (SOA), defined as the time period from IS to target onset. The onset of the IS preceded the onset of the target by $300 \mathrm{~ms}$ ( $\mathrm{SOA}=-300 \mathrm{~ms}$ ) or by $150 \mathrm{~ms}$ ( $\mathrm{SOA}=-150 \mathrm{~ms}$ ), or IS and target began simultaneously ( $\mathrm{SOA}=0 \mathrm{~ms}$ ), or IS onset followed target onset after $150 \mathrm{~ms}$ ( $\mathrm{SOA}=+150 \mathrm{~ms}$ ). The naming latencies were shorter in the begin-related condition than in the unrelated condition, provided that the ISs were presented at the SOA of $0 \mathrm{~ms}$ or the SOA of $+150 \mathrm{~ms}$. At negative SOAs the latencies in the two conditions did not differ significantly from each other. To account for these findings, we assume that on presentation of a given IS its phonological representation in the mental lexicon is activated. If IS and target are related in form, some of the target segments are already activated when the IS is 
processed. Apparently, this facilitates the phonological encoding of the target so that a shorter naming latency is observed than when an unrelated IS is presented. However, as the activation of the segments decays rapidly, such facilitatory effects only arise if the phonological encoding of the target promptly follows the processing of the related IS. If a related IS is presented too early, the activation of its segments has decayed again by the time the phonological encoding of the target begins, and no facilitatory effect is observed.

The new issue investigated in the present study was whether there would also be facilitatory effects from end-related ISs compared with unrelated ones, and if so, whether these effects would appear at the same SOAs as the effects of begin-related ISs or at different SOAs. If the two syllables of a disyllabic word are phonologically encoded in parallel, effects of beginand end-related ISs should appear at the same SOAs. By contrast, if the second syllable is encoded after the first, the effect of end-related ISs should begin to appear at a later SOA than the effect of begin-related ISs. Similarly, if different parts of a syllable are encoded in parallel, effects of begin- and endrelated ISs for monosyllabic words should appear at the same SOAs. If, however, different parts of a syllable are encoded at different times, the effects of the two types of ISs should arise at different SOAs.

The picture-word interference paradigm has been used in a number of other studies, for example by Glaser and Düngelhoff (1984), Lupker (1982), Posnansky and Rayner (1977), Rayner and Posnansky (1978), Rayner and Springer (1986), Rosinski (1977), and Underwood and Briggs (1984). In all of these studies, the ISs were presented visually. Words that are similar in sound are often also similar in spelling, and vice versa. When form-related and unrelated ISs are presented visually, the production of the targets can be affected via several routes (i.e., there can be effects of graphemic similarity between ISs and targets and independent effects of phonological similarity). Moreover, it is not certain that subjects always access the phonological representations of the ISs. As we wanted to ascertain the activation of the phonological representations of the ISs, we presented them auditorily, as we had done in earlier experiments (see Schriefers et al., 1990). Auditory IS presentation might induce the activation of graphemic in addition to phonological representations (see Seidenberg \& Tanenhaus, 1979), but this is not of critical importance for our experiments.

\section{Experiment 1}

\section{Method}

Subjects. Sixty-four paid subjects participated in the experiment. They were undergraduate students of Nijmegen University and native speakers of Dutch.

Materials. The experimental pictures were 25 line drawings of common objects. They were selected from a pool of pictures we had used in other experiments on lexical access in language production (see Levelt et al., 1991; Schriefers et al., 1990). Fifteen picture names were monosyllabic words, and nine were disyllabic words. One object with a trisyllabic name (radio ['ra:.di:.jo]) was inadvertently included in the materials. In the analyses this item was grouped with the disyllabic targets. Five disyllabic words and the trisyllabic word were stressed on the first syllable, and four disyllabic words were stressed on the second syllable.

For each target, a begin-related and an end-related IS were selected. The begin-related ISs for monosyllabic targets were other monosyllabic words that had the same onset and nucleus as the corresponding targets but different codas. The end-related ISs were monosyllabic words that shared the nucleus and coda but not the onset with the corresponding targets. The related ISs for disyllabic targets had either the same first or the same second syllable as the corresponding targets.

Each target was not only combined with two related ISs but also with two unrelated ones. In the unrelated conditions, the same words were used as in the related conditions, but new combinations of ISs and targets were created. Each target was combined with one of the begin-related and one of the end-related ISs selected for other targets with the same number of syllables. The unrelated ISs for monosyllabic targets shared neither onset nor nucleus or coda with the corresponding targets. The unrelated ISs for disyllabic targets also differed from the corresponding targets in most syllable constituents, but in two pairs, target and IS both included the schwa in the second syllable, and in four pairs, target and IS both ended with [r]. There were no obvious semantic relationships between the targets and the corresponding ISs. In addition to the experimental pictures, there were 20 practice pictures, each of which was combined with two unrelated ISs. The names of the experimental pictures and ISs are listed in the Appendix.

Design. Each target was combined with four ISs (begin-related, begin-unrelated, end-related, and end-unrelated ISs) and was also presented without an IS (silence condition). Therefore, the experimental design included a variable IS type with five levels. Each subject saw each of the 25 target pictures five times, once in combination with each of the four ISs and once without an IS. Thus, IS type was a within-subjects variable. The IS target combinations were presented under four SOAs ( $-300 \mathrm{~ms},-150 \mathrm{~ms}, 0 \mathrm{~ms}$, and $+150 \mathrm{~ms})$. SOA was a between-subjects variable. There were four groups of 16 subjects each who were tested with different SOAs.

Because there were 25 targets, each of which was presented under five IS conditions, the experiment included 125 different IS target combinations. The order of the targets was random, except that no target was repeated on successive trials. Four different target sequences were constructed, each of which was used for 4 subjects of each group. The order of the five IS conditions was counterbalanced across targets, according to a Latin square design. The experimental trials were preceded by 40 practice trials.

Apparatus. The target pictures were presented as white line drawings on a black background, using a Vector General display. The ISs were recorded and digitized with a sampling frequency of $10 \mathrm{kHz}$. They were stored on the disk of a PDP 11/55 computer and presented by means of Sennheiser MD211N headphones. The computer controlled the presentation of the targets and ISs and recorded the naming times, measured from target onset to the triggering of the voice key by the subject's response. The sessions were taped using a Revox A700 recorder.

Procedure. Subjects were tested individually. They were seated in a dimly lit soundproof booth at comfortable viewing distance in front of the display. After having read the instructions, they received a booklet showing the target pictures. Next to each object was printed the noun that the subjects in earlier experiments had spontaneously used most frequently to name the object. The subjects were asked to use only these names to refer to the pictures. As soon as they indicated that they had looked at all drawings and studied their names, the practice trials were administered; they were followed immediately by the experimental trials. The entire session took approximately 20 min.

The test trials had the following structure. Each target was presented for $400 \mathrm{~ms}$. Depending on the SOA condition, the onset of 
the IS coincided with the target onset, preceded it by $300 \mathrm{~ms}$ or 150 ms, or followed it after $150 \mathrm{~ms}$. In all SOA conditions, the time intervals between the onsets of successive targets were $3 \mathrm{~s}$. The subject named the target as quickly as possible, and the naming times were recorded. For technical reasons, naming times longer than $1 \mathrm{~s}$ could not be registered.

Data analysis. Trials on which subjects used picture names other than the expected ones, repaired their utterances, stuttered, or produced mouth clicks (i.e., clicking or smacking nonspeech sound produced by the lips or tongue) triggering the voice key were regarded as errors, as were responses with latencies exceeding $1,000 \mathrm{~ms}$. In the analyses of reaction times (RTs), errors were replaced by estimates following Winer (1971).

Separate analyses of variance (ANOVAs) were carried out for mono- and disyllabic targets. In these analyses, there was one betweensubjects variable, SOA, and one within-subject variable, IS type. We report $F^{\prime}$ values (see, e.g., Winer, 1971). Analyses of simple effects were performed to test the effect of IS type for each SOA. Dunnett's tests $(p<.05)$ were used to compare the related and unrelated conditions to the silence condition. Finally, differences between related and unrelated conditions were tested using planned comparisons (one-tailed $t$ tests).

\section{Results}

Error rates. As Table 1 shows, the error rates tended to be higher in conditions using unrelated ISs than in conditions using related ones. This held for monosyllabic as well as for disyllabic targets, for begin-related ISs and their controls as well as for end-related ISs and their controls, and for most SOAs. The RTs tended to be shorter in the related condition than in the unrelated condition. Thus, there was no speedaccuracy trade-off, but the reactions were, generally speaking, faster and less error prone in the related than in the unrelated condition.
In the ANOVA on error rates for monosyllabic targets, neither the main effects nor the interaction was significant, $F^{\prime}(6,124)=2.02, M S_{\mathrm{e}}=0.16, F^{\prime}(14,101)=0.77, M S_{\mathrm{e}}=$ 0.16 , and $F^{\prime}(37,402)=1.04, M S_{\mathrm{e}}=0.11$, for the effects of IS type, SOA, and the interaction, respectively. In the ANOVA for disyllabic targets, only the main effect of IS type was significant, $F^{\prime}(5,75)=3.12, p<.05, M S_{\mathrm{e}}=0.29, F^{\prime}(8$, $87)=1.17, M S_{\mathrm{e}}=0.24$, and $F^{\prime}(36,335)=1.14, M S_{\mathrm{e}}=0.15$, for the effects of IS type, SOA, and the interaction, respectively.

The reported error rates include RTs exceeding the 1000 ms deadline. Such outliers were more frequent in the unrelated than in the related condition, as were the remaining types of error. For monosyllabic targets, the outlier rates were $1.6 \%$ and $1.3 \%$ for the begin-related and end-related conditions, respectively, and $2.8 \%$ and $2.4 \%$ for the begin-unrelated and end-unrelated conditions, respectively; the outlier rate for the silence condition was $1.1 \%$. For disyllabic targets, the outlier rates were $3.5 \%$ and $2.8 \%$ for the begin-related and the end-related conditions, respectively, and $7.2 \%$ and $3.8 \%$ for the begin-unrelated and end-unrelated conditions, respectively; the outlier rate for the silence condition was $3.9 \%$. As more long latencies were excluded in the unrelated condition than in the related condition, and as the mean RT was longer in the unrelated condition than in the related condition, existing RT differences between the conditions were probably slightly underestimated. It should be noted, however, that this worked against our hypothesis rather than for it.

Reaction times. The mean RTs for mono- and disyllabic targets broken down by SOA and IS type are listed in Table 1. Figure 1 displays the differences between the mean naming latencies in the silence condition and each of the other IS conditions for mono- and disyllabic targets. Positive values

Table 1

Results of Experiment 1: Mean Reaction Times (RTs in Milliseconds) and Error Rates (E\%) per Stimulus Onset Asynchrony (SOA) and Interfering Stimulus (IS) Type for Monosyllabic and Disyllabic Targets

\begin{tabular}{|c|c|c|c|c|c|c|c|c|c|c|}
\hline \multirow[b]{3}{*}{ IS type } & \multicolumn{5}{|c|}{ Monosyllabic targets } & \multicolumn{5}{|c|}{ Disyllabic targets } \\
\hline & \multicolumn{4}{|c|}{ SOA } & \multirow[b]{2}{*}{$M$} & \multicolumn{4}{|c|}{ SOA } & \multirow[b]{2}{*}{$M$} \\
\hline & -300 & -150 & 0 & +150 & & -300 & -150 & 0 & +150 & \\
\hline $\begin{array}{l}\text { Begin related } \\
\text { RT } \\
\text { E\% }\end{array}$ & $\begin{array}{r}617 \\
7.1\end{array}$ & $\begin{array}{l}608 \\
6.7\end{array}$ & $\begin{array}{r}586 \\
4.2\end{array}$ & $\begin{array}{r}564 \\
5.0\end{array}$ & $\begin{array}{r}594 \\
5.7\end{array}$ & $\begin{array}{c}670 \\
10.0\end{array}$ & $\begin{array}{r}687 \\
9.4\end{array}$ & $\begin{array}{r}636 \\
8.1\end{array}$ & $\begin{array}{l}601 \\
7.5\end{array}$ & $\begin{array}{c}648 \\
8.7\end{array}$ \\
\hline RT & $\begin{array}{r}612 \\
6.7\end{array}$ & $\begin{array}{r}642 \\
6.3\end{array}$ & $\begin{array}{r}632 \\
7.5\end{array}$ & $\begin{array}{c}625 \\
11.7\end{array}$ & $\begin{array}{r}628 \\
8.0\end{array}$ & $\begin{array}{l}675 \\
14.4\end{array}$ & $\begin{array}{l}701 \\
11.2\end{array}$ & $\begin{array}{c}673 \\
21.9\end{array}$ & $\begin{array}{l}663 \\
18.1\end{array}$ & $\begin{array}{c}678 \\
16.4\end{array}$ \\
\hline $\begin{array}{l}\text { End related } \\
\text { RT } \\
\text { E\% }\end{array}$ & $\begin{array}{r}597 \\
4.6\end{array}$ & $\begin{array}{r}601 \\
2.5\end{array}$ & $\begin{array}{r}600 \\
5.8\end{array}$ & $\begin{array}{r}606 \\
5.4\end{array}$ & $\begin{array}{r}601 \\
4.6\end{array}$ & $\begin{array}{l}653 \\
9.4\end{array}$ & $\begin{array}{r}660 \\
6.9\end{array}$ & $\begin{array}{r}647 \\
9.4\end{array}$ & $\begin{array}{r}645 \\
6.9\end{array}$ & $\begin{array}{r}651 \\
8.1\end{array}$ \\
\hline $\begin{array}{l}\text { End unrelated } \\
\text { RT } \\
\text { E\% } \\
\text { Silence }\end{array}$ & $\begin{array}{r}612 \\
6.7\end{array}$ & $\begin{array}{r}628 \\
8.7\end{array}$ & $\begin{array}{c}613 \\
9.2\end{array}$ & $\begin{array}{r}613 \\
8.3\end{array}$ & $\begin{array}{r}617 \\
8.2\end{array}$ & $\begin{array}{l}665 \\
7.5\end{array}$ & $\begin{array}{r}673 \\
7.5\end{array}$ & $\begin{array}{r}662 \\
8.7\end{array}$ & $\begin{array}{c}633 \\
13.8\end{array}$ & $\begin{array}{r}658 \\
9.4\end{array}$ \\
\hline $\begin{array}{l}\text { Silence } \\
\text { RT } \\
\text { E\% } \\
M\end{array}$ & $\begin{array}{r}603 \\
4.2\end{array}$ & $\begin{array}{r}590 \\
5.8\end{array}$ & $\begin{array}{r}557 \\
3.8\end{array}$ & $\begin{array}{l}573 \\
6.3\end{array}$ & $\begin{array}{r}581 \\
5.0\end{array}$ & $\begin{array}{r}639 \\
6.9\end{array}$ & $\begin{array}{r}642 \\
6.3\end{array}$ & $\begin{array}{c}613 \\
10.0\end{array}$ & $\begin{array}{l}616 \\
8.1\end{array}$ & $\begin{array}{r}628 \\
7.8\end{array}$ \\
\hline $\begin{array}{l}\text { RT } \\
\text { E\% }\end{array}$ & $\begin{array}{r}608 \\
5.8 \\
\end{array}$ & $\begin{array}{r}614 \\
6.0\end{array}$ & $\begin{array}{r}597 \\
6.1\end{array}$ & $\begin{array}{r}596 \\
7.3\end{array}$ & $\begin{array}{r}604 \\
6.3\end{array}$ & $\begin{array}{c}660 \\
9.6\end{array}$ & $\begin{array}{r}673 \\
8.3\end{array}$ & $\begin{array}{c}646 \\
11.6\end{array}$ & $\begin{array}{c}632 \\
10.9 \\
\end{array}$ & $\begin{array}{c}653 \\
10.0 \\
\end{array}$ \\
\hline
\end{tabular}



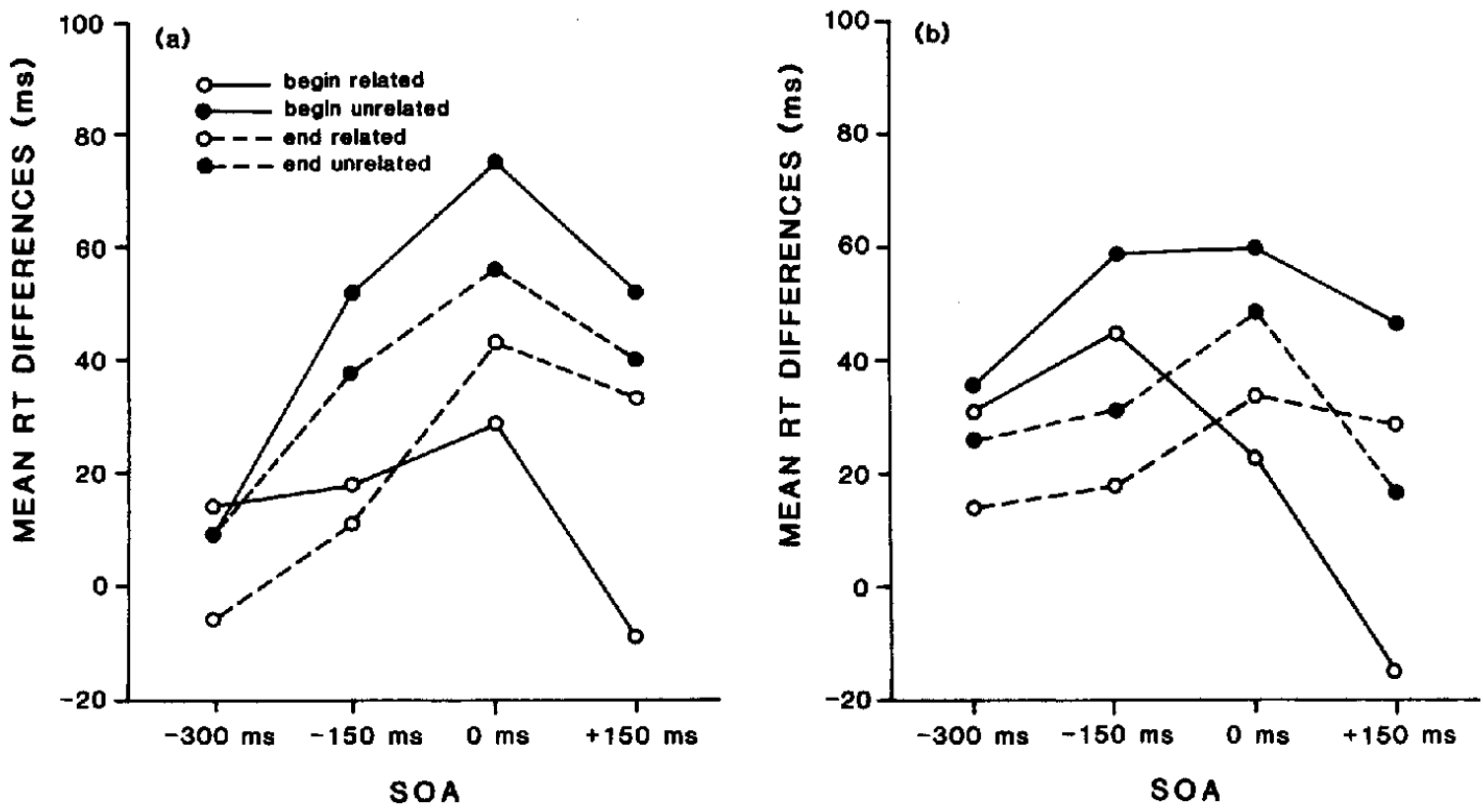

Figure 1. Results of Experiment 1: Mean reaction time (RT) differences (in milliseconds) between the silence condition and the begin-related, begin-unrelated, end-related, and end-unrelated conditions at the SOAs of $-300 \mathrm{~ms},-150 \mathrm{~ms}, 0 \mathrm{~ms}$, and $+150 \mathrm{~ms}$ for (a) monosyllabic targets and (b) disyllabic targets. (Positive values indicate interference relative to the silence condition, and negative values indicate facilitation.)

indicate naming latencies longer than those in the silence condition, and negative values indicate latencies shorter than those in the silence condition.

For monosyllabic targets, the main effect of IS type and the interaction of IS type and SOA were significant, $F^{\prime}(4,107)=$ $9.45, p<.01, \mathrm{MS}_{\mathrm{e}}=35,576$, and $F^{\prime}(15,408)=3.25, p<$ $.01, M S_{\mathrm{e}}=17,060$, respectively. The main effect of SOAs was not significant, $F^{\prime}(3,66)=0.55, M S_{e}=170,683$. The significant interaction reveals that the effects of the ISs depended on the relative timing of target and IS presentation. Analyses of simple effects showed that the effect of IS type was significant at the $1 \%$ level for each SOA. Figure 1 shows, however, that the differences between the ISs were less pronounced at an SOA of $-300 \mathrm{~ms}$ than at the remaining SOAs.

In comparison with the silence condition, the presentation of ISs tended to slow down the naming responses. Dunnett's tests showed that at an SOA of $-300 \mathrm{~ms}$, none of the related or unrelated IS conditions differed significantly from the silence baseline, but at the remaining SOAs, practically all differences were significant $(p<.05)$; exceptions were the differences between the silence condition and the begin-related and end-related conditions at an SOA of $-150 \mathrm{~ms}$ and the difference between silence and the begin-related condition at an SOA of $+150 \mathrm{~ms}$.

The central question investigated in Experiment 1 was whether the RTs in the related and unrelated conditions would deviate from each other and, if so, at which SOAs this would be the case. As can be seen from Figure 1, begin-related ISs generally interfered less with the naming task than beginunrelated ISs. In other words, the naming of the target pictures was facilitated in the begin-related condition in relation to the begin-unrelated condition. The mean RT was significantly shorter $(p<.01)$ in the begin-related than in the beginunrelated condition at all SOAs, with the exception of an SOA of $-300 \mathrm{~ms}$. The mean RTs in the end-related conditions were likewise shorter than the mean RTs in the end-unrelated condition, but this difference was only significant at an SOA of $-150 \mathrm{~ms}(p<.05)$.

The pattern of results for disyllabic targets closely resembles the pattern for monosyllabic targets. The main effect of IS type was significant, $F^{\prime}(4,84)=7.55, p<.01, M S_{\mathrm{e}}=29,439$, as was the interaction of IS type and SOA, $F^{\prime}(19,334)=$ $2.03, p<.01, M S_{\mathrm{e}}=17,787$. The effect of SOA was not significant, $F^{\prime}(3,73)=1.86, M S_{c}=140,715$. Analyses of simple effects revealed that the effect of IS type was significant at each SOA $(p<.01)$. As Figure 1 shows, the RTs were generally longer when ISs were presented than when, in the silence condition, this was not the case. Dunnett's tests $(p<$ .05 ) showed that at an SOA of $-300 \mathrm{~ms}$, this interference effect was only significant for the begin-unrelated condition; at an SOA of $-150 \mathrm{~ms}$, it was significant for the begin-related and the begin-unrelated conditions, and at an SOA of $0 \mathrm{~ms}$, it was significant for the begin-unrelated, end-related and endunrelated conditions. Finally, at an SOA of $+150 \mathrm{~ms}$, the difference was significant for the end-related and the beginunrelated conditions.

As had been found for monosyllabic targets, the mean RTs were shorter in the related than in the unrelated conditions, and again, this difference was more pronounced for beginrelated and begin-unrelated ISs than for end-related and end- 
unrelated ISs. Planned comparisons showed that the difference between the begin-related and begin-unrelated conditions was significant at an SOA of $0 \mathrm{~ms}$ and at an SOA of $+150 \mathrm{~ms}(p<.01$ in both cases). The difference between the end-related and end-unrelated conditions was not significant at any SOA.

\section{Discussion}

The results of Experiment 1 replicate some findings of a study we had carried out earlier (Schriefers et al., 1990). First, the mean RTs were generally longer when ISs were presented than when this was not the case. The preparation of the naming responses was apparently disrupted by the presentation of irrelevant words. Second, the strength of this interference effect depended, among other things, on the phonological form of the ISs. The interference was stronger for beginunrelated than for begin-related stimuli. In other words, in comparison with begin-unrelated ISs, begin-related ones facilitated target naming. This held, however, only for the SOAs of $-150 \mathrm{~ms}, 0 \mathrm{~ms}$, and $+150 \mathrm{~ms}$ for monosyllabic targets and for the SOAs of $0 \mathrm{~ms}$ and $+150 \mathrm{~ms}$ for disyllabic targets. No systematic effect of the phonological form of the ISs was obtained at earlier SOAs. Presumably, when a begin-related IS was presented, some of the target segments were activated, which facilitated the phonological encoding of the target, provided that it followed the IS promptly. When the IS was presented too early, its phonological representation had probably decayed again before the target was phonologically encoded so that no facilitatory effect was observed. The naming responses also tended to be facilitated in the end-related conditions in comparison with the unrelated ones, but this effect was weaker than the effect in the begin-related conditions and only reached significance at the SOA of $-150 \mathrm{~ms}$ for monosyllabic targets.

In Experiment 1, 50\% of the ISs were related in form to the corresponding targets. Because of the high proportion of related IS target pairs, the subjects might have tried to use the ISs strategically. At negative SOAs they might, for example, have used the ISs to predict the upcoming targets. Or they might, before uttering a given picture name, have checked whether it was related in form to the IS and might have hesitated when this was not the case. To discover whether such strategies contributed to the effects, we ran the second experiment, in which each target picture was not only combined with each of the related and unrelated ISs of the first experiment, but also with five new unrelated ISs. Thereby, the proportion of related IS target pairs in the materials presented to each subject was reduced from $50 \%$ to $22 \%$, which should discourage the subjects from attempts to use the ISs strategically.

\section{Experiment 2}

\section{Method}

Subjects. Sixty-four subjects participated in the experiment. They were drawn from the same subject pool as the subjects of Experiment 1 , but none of them had participated in that experiment.
Materials. The materials of the second experiment included the targets and ISs of the first experiment. In addition, each picture was combined with five new ISs, namely, two new nouns, an adjective, a verb, and a function word. All new ISs were unrelated in form to the corresponding targets. In the first experiment, monosyllabic targets were only combined with monosyllabic ISs and disyllabic targets with disyllabic ISs so that the subjects could predict the length of the target names on the basis of the ISs. Because of the inclusion of the new unrelated ISs, this was not possible in the present experiment.

Each picture was presented 10 times, without an IS, with the beginrelated and end-related ISs and the corresponding unrelated ISs, and with the five new unrelated ISs. Trials on which the new unrelated ISs were presented were filler trials. The procedure was the same as in the first experiment.

\section{Results}

Error rates. As in the first experiment, error rates were higher in conditions using unrelated ISs than in conditions using related ones (see Table 2). In the ANOVA for monosyllabic targets, the main effect of IS type was significant, $F^{\prime}(6,135)=2.29, p<.05, M S_{c}=0.12$. The main effect of SOA and the interaction of IS type and SOA were not significant, $F^{\prime}(5,94)=1.34, M S_{\mathrm{e}}=0.21$, for SOA and $F^{\prime}(59$, $402)=0.97, M S_{c}=0.09$, for the interaction. In the analysis for disyllabic targets, both main effects were significant, $F^{\prime}(6$, $315)=2.16, p<.05, M S_{\mathrm{e}}=0.13$, for IS type and $F^{\prime}(4,87)$ $=3.13, p<.05, M S_{e}=0.24$, for SOA. The interaction was not significant, $F^{\prime}(29,315)=1.43, M S_{e}=0.13$.

Reaction times. In the ANOVA on the RTs for monosyllabic targets, the main effect of IS type and the interaction of IS type and SOA were significant, $F^{\prime}(4,84)=10.11, p<.01$, $M S_{\mathrm{e}}=28,250$, for the effect of IS type, $F^{\prime}(17,389)=2.96, p$ $<.01, M S_{\mathrm{e}}=11,126$, for the interaction. The main effect of SOA was not significant, $F^{\prime}(3,69)=0.61, M S_{e}=176,308$. Analyses of simple effects revealed that the effect of IS type was significant at each SOA $(p<.01$; see Table 2 and Figure 2).

Dunnett's test showed that at the SOA of $-300 \mathrm{~ms}$, none of the related or unrelated conditions differed significantly from the silence condition. By contrast, at the remaining SOAs the RTs were significantly longer in most related and unrelated IS conditions than in the silence condition. The only exceptions were the difference between the end-related and the silence conditions at the SOA of $-150 \mathrm{~ms}$ and the difference between the begin-related and the silence conditions at the SOA of $+150 \mathrm{~ms}$.

As in the first experiment, the mean RTs tended to be shorter in the related than in the unrelated conditions. Planned comparisons showed that the difference between the begin-related and the begin-unrelated conditions was significant at the SOA of $-150 \mathrm{~ms}(p<.05)$, at the SOA of $0 \mathrm{~ms}$ $(p<.01)$, and at the SOA of $+150 \mathrm{~ms}(p<.01)$. The difference between the end-related and the end-unrelated conditions was significant at the SOA of $-150 \mathrm{~ms}$ and at the SOA of $0 \mathrm{~ms}$ ( $p<.01$ in both cases).

In the ANOVA for disyllabic targets the main effect of IS type and the interaction of SOA and IS type were likewise significant, $F^{\prime}(4,60)=7.45, p<.01, M S_{\mathrm{e}}=37,276$, for IS type and $F^{\prime}(16,303)=2.97, p<.01, M S_{e}=16,785$, for the 
Table 2

Results of Experiment 2: Mean Reaction Times (RTs in Milliseconds) and Error Rates (E\%) per Stimulus Onset Asynchrony (SOA) and Interfering Stimulus (IS) Type for Monosyllabic and Disyllabic Targets

\begin{tabular}{|c|c|c|c|c|c|c|c|c|c|c|}
\hline \multirow[b]{3}{*}{ IS type } & \multicolumn{5}{|c|}{ Monosyllabic targets } & \multicolumn{5}{|c|}{ Disyllabic targets } \\
\hline & \multicolumn{4}{|c|}{ SOA } & \multirow[b]{2}{*}{$M$} & \multicolumn{4}{|c|}{ SOA } & \multirow[b]{2}{*}{$M$} \\
\hline & -300 & -150 & 0 & +150 & & -300 & -150 & 0 & +150 & \\
\hline $\begin{array}{l}\text { Begin related } \\
\text { RT } \\
\text { E\% }\end{array}$ & $\begin{array}{l}569 \\
3.8\end{array}$ & $\begin{array}{c}566 \\
7.5\end{array}$ & $\begin{array}{l}570 \\
6.7\end{array}$ & $\begin{array}{l}541 \\
3.8\end{array}$ & $\begin{array}{r}562 \\
5.4\end{array}$ & $\begin{array}{r}632 \\
8.1\end{array}$ & $\begin{array}{r}621 \\
6.3\end{array}$ & $\begin{array}{l}586 \\
13.1\end{array}$ & $\begin{array}{l}570 \\
5.6\end{array}$ & $\begin{array}{r}602 \\
8.3\end{array}$ \\
\hline $\begin{array}{l}\text { Begin unrelated } \\
\text { RT } \\
\text { E\% } \\
\text { End related }\end{array}$ & $\begin{array}{l}578 \\
4.2\end{array}$ & $\begin{array}{c}584 \\
10.0\end{array}$ & $\begin{array}{c}609 \\
9.2\end{array}$ & $\begin{array}{l}591 \\
9.2\end{array}$ & $\begin{array}{l}591 \\
8.1\end{array}$ & $\begin{array}{r}629 \\
7.5\end{array}$ & $\begin{array}{r}636 \\
8.1\end{array}$ & $\begin{array}{c}647 \\
19.4\end{array}$ & $\begin{array}{c}606 \\
11.2\end{array}$ & $\begin{array}{l}630 \\
11.6\end{array}$ \\
\hline $\begin{array}{l}\text { RT } \\
\text { E\% }\end{array}$ & $\begin{array}{r}552 \\
4.2\end{array}$ & $\begin{array}{r}544 \\
4.2\end{array}$ & $\begin{array}{l}576 \\
6.3\end{array}$ & $\begin{array}{l}568 \\
5.0\end{array}$ & $\begin{array}{l}560 \\
4.9\end{array}$ & $\begin{array}{r}616 \\
5.0\end{array}$ & $\begin{array}{l}599 \\
4.4\end{array}$ & $\begin{array}{r}607 \\
7.5\end{array}$ & $\begin{array}{l}620 \\
10.0\end{array}$ & $\begin{array}{r}611 \\
6.7\end{array}$ \\
\hline $\begin{array}{l}\text { End unrelated } \\
\text { RT } \\
\text { E\% } \\
\text { Silence }\end{array}$ & $\begin{array}{r}566 \\
4.2\end{array}$ & $\begin{array}{l}571 \\
5.8\end{array}$ & $\begin{array}{r}601 \\
6.7\end{array}$ & $\begin{array}{r}574 \\
7.1\end{array}$ & $\begin{array}{r}578 \\
5.9\end{array}$ & $\begin{array}{l}618 \\
5.6\end{array}$ & $\begin{array}{r}608 \\
6.3\end{array}$ & $\begin{array}{c}629 \\
16.2\end{array}$ & $\begin{array}{r}613 \\
8.7\end{array}$ & $\begin{array}{r}617 \\
9.2\end{array}$ \\
\hline $\begin{array}{l}\text { Silence } \\
\text { RT } \\
\text { E\% } \\
M\end{array}$ & $\begin{array}{r}555 \\
2.9\end{array}$ & $\begin{array}{l}539 \\
4.2\end{array}$ & $\begin{array}{r}548 \\
5.8\end{array}$ & $\begin{array}{l}544 \\
2.9\end{array}$ & $\begin{array}{l}546 \\
4.0\end{array}$ & $\begin{array}{r}582 \\
6.3\end{array}$ & $\begin{array}{r}564 \\
6.3\end{array}$ & $\begin{array}{r}575 \\
6.3\end{array}$ & $\begin{array}{r}577 \\
6.9\end{array}$ & $\begin{array}{c}575 \\
6.4\end{array}$ \\
\hline $\begin{array}{l}\text { RT } \\
\text { E\% } \\
\end{array}$ & $\begin{array}{r}564 \\
3.8\end{array}$ & $\begin{array}{r}561 \\
6.3\end{array}$ & $\begin{array}{r}581 \\
6.9 \\
\end{array}$ & $\begin{array}{r}564 \\
5.6 \\
\end{array}$ & $\begin{array}{r}567 \\
5.7 \\
\end{array}$ & $\begin{array}{r}615 \\
6.5 \\
\end{array}$ & $\begin{array}{r}506 \\
6.3 \\
\end{array}$ & $\begin{array}{l}609 \\
12.5 \\
\end{array}$ & $\begin{array}{r}597 \\
8.5\end{array}$ & $\begin{array}{r}607 \\
8.4\end{array}$ \\
\hline
\end{tabular}

interaction. The effect of SOA was not significant, $F^{\prime}(5,69)$ $=0.43, M S_{e}=134,981$. Analyses of simple effects showed that the effect of IS type was again significant at each SOA $(p<.01)$.
As Figure 2 shows, the presentation of ISs tended to slow down the naming responses in relation to those in the silence condition. Dunnett's tests, carried out separately for each SOA, showed that practically all differences between the si-
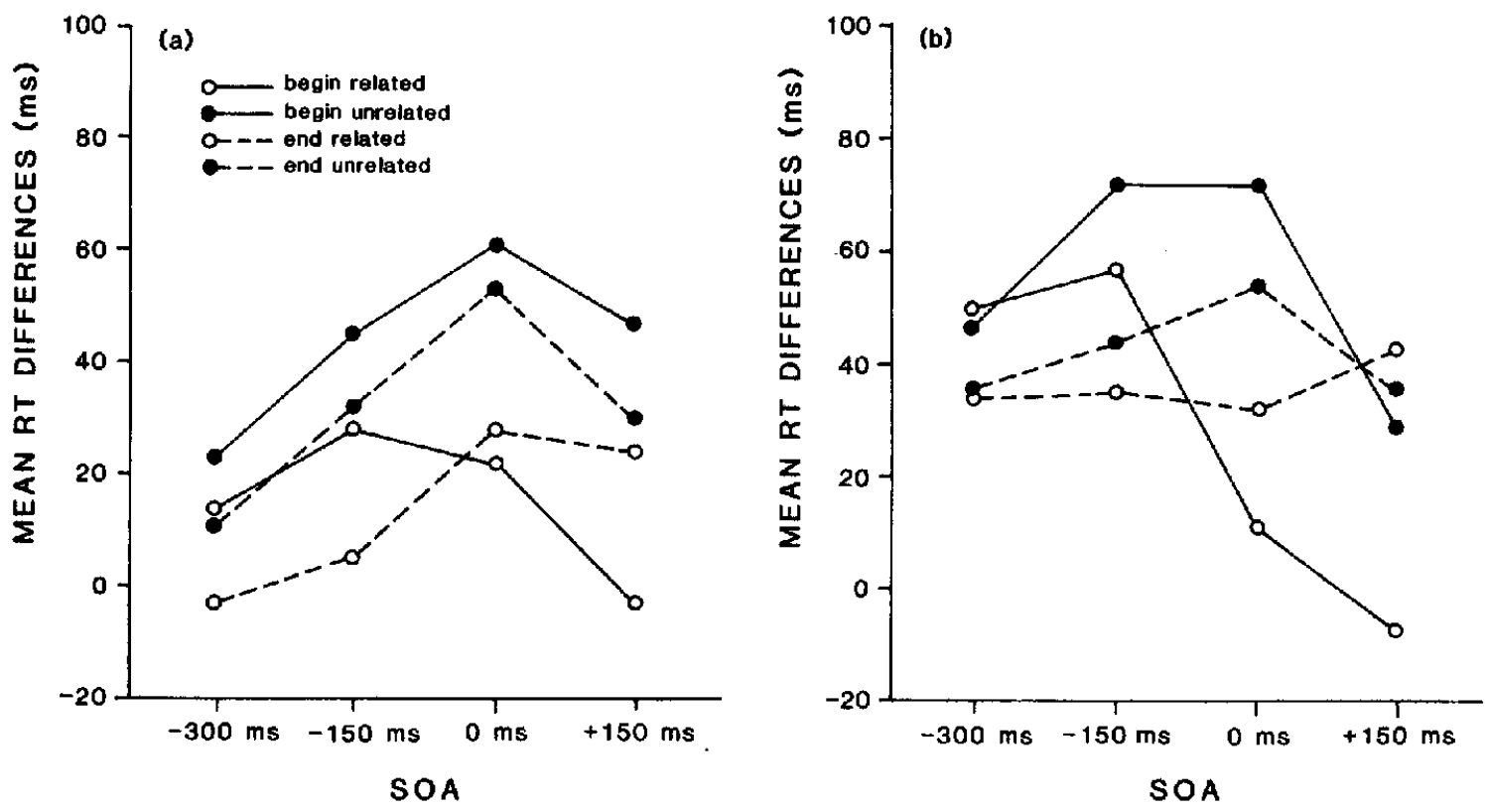

Figure 2. Results of Experiment 2: Mean reaction time (RT) differences (in milliseconds) between the silence condition and the begin-related, begin-unrelated, end-related, and end-unrelated conditions at the SOAs of $-300 \mathrm{~ms},-150 \mathrm{~ms}, 0 \mathrm{~ms}$, and $+150 \mathrm{~ms}$ for (a) monosyllabic targets and (b) disyllabic targets. (Positive values indicate interference relative to the silence condition, and negative values indicate facilitation.) 
lence condition and each of the other four conditions were significant $(p<.05)$; exceptions were the comparisons of the silence condition to the begin-related condition at the SOA of $0 \mathrm{~ms}$ and at the SOA of $+150 \mathrm{~ms}$ and to the begin-unrelated condition at the SOA of +150 ms.

The RTs were again shorter in the related than in the unrelated conditions. Planned comparisons revealed that the difference between the begin-related and the begin-unrelated conditions was significant at the SOA of $0 \mathrm{~ms}$ and at the SOA of $+150 \mathrm{~ms}(p<.01)$. The difference between the end-related and end-unrelated conditions was not significant at any SOA.

\section{Discussion}

The results of Experiment 2 closely resemble those of Experiment 1. The RTs again tended to be shorter on trials with related ISs than on trials with unrelated ISs. Effects of approximately the same magnitude were observed in the same SOA range as in the first experiment. The experiments differed in the percentage of related IS target pairs. Because this difference hardly affected the results, it is unlikely that the facilitatory effect of related ISs (in comparison with unrelated ISs) was mainly due to strategic processes, such as attempts to predict the upcoming targets on the basis of the ISs. This conclusion is also supported by the observation that the difference between the begin-related and the begin-unrelated conditions was strongest at positive SOAs. If the facilitatory effect were due to strategic processes, it should be most pronounced at the longest negative SOA (SOA $=-300 \mathrm{~ms}$ ), where most time was allowed for strategic processing of the ISs.

We already knew from earlier experiments that the beginrelated ISs facilitated target naming in relation to the unrelated ones. The present experiments were carried out to determine whether facilitation could also be obtained from end-related ISs and whether this effect would appear at the same SOAs as the effect of begin-related ISs or at different SOAs. In Experiments 1 and 2, the naming of monosyllabic targets was indeed facilitated by end-related ISs at certain SOAs. For disyllabic targets, the difference between endrelated and end-unrelated ISs never reached significance. However, in both experiments the mean naming times for disyllabic targets were shorter in the end-related than in the end-unrelated conditions across the entire SOA range.

By definition, begin- and end-related ISs differed in the word positions of the segments they shared with the targets. Consequently, they also differed in the timing of these critical segments in relation to the target onset. For example, at the SOA of $0 \mathrm{~ms}$, the critical segments in the begin-related condition began exactly at target onset. The critical segments in the end-related condition began a little later, after completion of the preceding noncritical segments. Because the duration of these segments varied across items, the timing of the critical segments in relation to the target onset was also variable. In the end-related condition, the critical segments in monosyllabic ISs began on average $118 \mathrm{~ms}$ after word onset, with a standard deviation of $45 \mathrm{~ms}$. In disyllabic ISs they began on average $268 \mathrm{~ms}$ after word onset, with a standard deviation of $52 \mathrm{~ms}$. It is possible that the strength of the facilitatory effect of a given related IS depends on the timing of the critical segments rather than on the timing of the onset of the interfering word. In the end-related condition, a systematic effect of SOA variation was probably overridden by effects of between-items variation in the timing of the critical segments. To test this hypothesis, we presented the ISs of Experiment 3 in such a way that at each SOA the critical segments of all ISs began exactly at the same times in relation to the target onset.

\section{Experiment 3}

\section{Method}

Subjects. Sixty-four subjects participated in the experiment. They were drawn from the same subject pool as the subjects of Experiments 1 and 2 but had not participated in those experiments.

Materials and procedure. The same materials were used as in Experiment 2. Whereas in Experiments 1 and 2, SOAs were defined as the time intervals between the onsets of the targets and the onsets of the ISs, in the present experiment they were defined as the time intervals between the onsets of the critical segments included in the ISs and the targets. Again, four SOAs were tested: $-300 \mathrm{~ms},-150$ $\mathrm{ms}, 0 \mathrm{~ms}$, and $+150 \mathrm{~ms}$.

To decide when the ISs should be presented, we determined the duration of the segments preceding the critical segments for each endrelated IS. Thus, for each monosyllabic IS, the duration of the onset consonant and for each disyllabic IS the duration of the first syllable was measured. Segment durations were measured on digitized waveforms, using visual and auditory evidence of the word onsets and of the onsets of the critical segments.

The SOAs in the end-related condition were adjusted separately for each IS in such a way that the critical segments began at target onset (SOA $=0 \mathrm{~ms}$ ) or $150 \mathrm{~ms}$ or $300 \mathrm{~ms}$ before target onset (SOA $=-150 \mathrm{~ms}$ and $\mathrm{SOA}=-300 \mathrm{~ms}$, respectively) or $150 \mathrm{~ms}$ after target onset ( $\mathrm{SOA}=+150 \mathrm{~ms})$. In the end-unrelated condition, the same ISs were used with the same SOA adjustments as in the end-related condition, but the ISs were combined with different target pictures.

All ISs serving as fillers began at the same times in relation to the target onset. The onset time of the ISs on filler trials was the mean onset time across the experimental trials. For instance, at the SOA of $0 \mathrm{~ms}$, IS onset and target onset coincided on 50 experimental trials, and on 50 experimental trials, IS onset preceded target onset by an average of $186 \mathrm{~ms}$. Thus, the mean IS onset time across experimental trials, which was used as IS onset time for filler trials, was $93 \mathrm{~ms}$ before target onset. The onset times for the ISs on filler trials at other SOAs were determined in the same way.

\section{Results}

Error rates. In the ANOVAs on error rates, neither the main effects nor any of the interactions were significant, $F^{\prime}(32,101)=0.83, M S_{\mathrm{e}}=0.08, F^{\prime}(77,139)=0.49, M S_{\mathrm{e}}=$ 0.11 , and $F^{\prime}(76,399)=0.82, M S_{e}=0.08$, for the main effects of SOA and IS type and the interaction in the analysis of monosyllabic targets, respectively, and $F^{\prime}(6,79)=1.88, M S_{\text {e }}$ $=0.17, F^{\prime}(10,43)=1.94, M S_{\mathrm{e}}=0.09$, and $F^{\prime}(43,313)=$ $0.95, M S_{c}=0.15$, for SOA, IS type, and their interaction in the analysis of disyllabic targets, respectively; for mean error rates, see Table 3.

Reaction times. In the ANOVA for monosyllabic targets, the main effect of IS type and the interaction of IS type and SOA were significant, $F^{\prime}(4,85)=11.24, M S_{\mathrm{e}}=33,477, p<$ 
Table 3

Results of Experiment 3: Mean Reaction Times (RTs in Milliseconds) and Error Rates (E\%) per Stimulus Onset Asynchrony (SOA) and Interfering Stimulus (IS) Type for Monosyllabic and Disyllabic Targets

\begin{tabular}{|c|c|c|c|c|c|c|c|c|c|c|}
\hline \multirow[b]{3}{*}{ IS type } & \multicolumn{5}{|c|}{ Monosyllabic targets } & \multicolumn{5}{|c|}{ Disyllabic targets } \\
\hline & \multicolumn{4}{|c|}{ SOA } & \multirow[b]{2}{*}{$M$} & \multicolumn{4}{|c|}{ SOA } & \multirow[b]{2}{*}{$M$} \\
\hline & -300 & -150 & 0 & +150 & & -300 & -150 & 0 & +150 & \\
\hline $\begin{array}{l}\text { Begin related } \\
\text { RT } \\
\text { E\% }\end{array}$ & $\begin{array}{l}579 \\
4.6\end{array}$ & $\begin{array}{l}590 \\
5.4\end{array}$ & $\begin{array}{r}585 \\
5.4\end{array}$ & $\begin{array}{r}544 \\
4.6\end{array}$ & $\begin{array}{r}574 \\
5.0\end{array}$ & $\begin{array}{r}636 \\
6.9\end{array}$ & $\begin{array}{c}657 \\
10.0\end{array}$ & $\begin{array}{c}627 \\
10.0\end{array}$ & $\begin{array}{r}584 \\
5.6\end{array}$ & $\begin{array}{r}626 \\
8.1\end{array}$ \\
\hline $\begin{array}{l}\text { Begin unrelated } \\
\text { RT } \\
\text { E\% }\end{array}$ & $\begin{array}{r}592 \\
5.8\end{array}$ & $\begin{array}{r}617 \\
3.8\end{array}$ & $\begin{array}{r}624 \\
6.7\end{array}$ & $\begin{array}{r}597 \\
3.3\end{array}$ & $\begin{array}{r}608 \\
4.9\end{array}$ & $\begin{array}{l}646 \\
10.6\end{array}$ & $\begin{array}{c}688 \\
13.8\end{array}$ & $\begin{array}{l}670 \\
10.6\end{array}$ & $\begin{array}{r}635 \\
6.9\end{array}$ & $\begin{array}{l}660 \\
10.5\end{array}$ \\
\hline $\begin{array}{l}\text { End related } \\
\text { RT } \\
\text { E\% }\end{array}$ & $\begin{array}{l}556 \\
5.4\end{array}$ & $\begin{array}{r}561 \\
3.8\end{array}$ & $\begin{array}{l}558 \\
2.9\end{array}$ & $\begin{array}{r}566 \\
5.4\end{array}$ & $\begin{array}{r}561 \\
4.4\end{array}$ & $\begin{array}{c}617 \\
13.1\end{array}$ & $\begin{array}{r}612 \\
8.1\end{array}$ & $\begin{array}{r}604 \\
8.7\end{array}$ & $\begin{array}{r}614 \\
3.1\end{array}$ & $\begin{array}{r}612 \\
8.3\end{array}$ \\
\hline $\begin{array}{l}\text { End unrelated } \\
\text { RT } \\
\text { E\% }\end{array}$ & $\begin{array}{r}562 \\
4.2\end{array}$ & $\begin{array}{r}573 \\
4.2\end{array}$ & $\begin{array}{r}597 \\
3.8\end{array}$ & $\begin{array}{l}594 \\
4.6\end{array}$ & $\begin{array}{l}581 \\
4.2\end{array}$ & $\begin{array}{c}606 \\
10.0\end{array}$ & $\begin{array}{l}602 \\
6.9\end{array}$ & $\begin{array}{r}642 \\
7.5\end{array}$ & $\begin{array}{r}642 \\
8.1\end{array}$ & $\begin{array}{c}623 \\
8.1\end{array}$ \\
\hline $\begin{array}{c}\text { Silence } \\
\text { RT } \\
\text { E\% } \\
M\end{array}$ & $\begin{array}{l}562 \\
5.4\end{array}$ & $\begin{array}{r}566 \\
3.8\end{array}$ & $\begin{array}{r}561 \\
5.4\end{array}$ & $\begin{array}{l}549 \\
4.2\end{array}$ & $\begin{array}{r}560 \\
4.7\end{array}$ & $\begin{array}{l}590 \\
7.5\end{array}$ & $\begin{array}{l}589 \\
5.6\end{array}$ & $\begin{array}{l}583 \\
8.1\end{array}$ & $\begin{array}{l}579 \\
5.6\end{array}$ & $\begin{array}{r}585 \\
6.7\end{array}$ \\
\hline $\begin{array}{l}\text { RT } \\
\text { E\% }\end{array}$ & $\begin{array}{r}570 \\
5.1\end{array}$ & $\begin{array}{r}582 \\
4.2\end{array}$ & $\begin{array}{r}585 \\
4.8\end{array}$ & $\begin{array}{l}570 \\
4.4\end{array}$ & $\begin{array}{r}577 \\
4.6 \\
\end{array}$ & $\begin{array}{c}619 \\
9.6\end{array}$ & $\begin{array}{r}629 \\
8.9 \\
\end{array}$ & $\begin{array}{r}625 \\
9.0 \\
\end{array}$ & $\begin{array}{r}611 \\
5.9 \\
\end{array}$ & $\begin{array}{r}621 \\
8.3 \\
\end{array}$ \\
\hline
\end{tabular}

.01 , for the main effect and $F^{\prime}(15,381)=3.50, M S_{\mathrm{e}}=14,092$, $p<.01$, for the interaction. The main effect of SOA was not significant, $F^{\prime}(4,69)=0.48, M S_{e}=166,956$. In the analysis of simple effects, the effect of IS type was significant at each SOA $(p<.01)$. As in the previous experiments, naming times tended to be longer when ISs were present than when this was not the case. Dunnett's tests $(p<.05)$ showed that at the SOA of $-300 \mathrm{~ms}$, only the begin-unrelated condition differed significantly from the silence condition. At the SOA of -150 $\mathrm{ms}$, the begin-related and begin-unrelated conditions, and at the SOA of $0 \mathrm{~ms}$ the begin-related, begin-unrelated, and endunrelated conditions differed significantly from the silence condition. Finally, at the SOA of $+150 \mathrm{~ms}$, the begin-unrelated, end-related, and end-unrelated conditions differed significantly from silence (see Table 3 and Figure 3 ).

As Figure 3 shows, the pattern of results obtained for the begin-related condition and its control is exactly the same as in Experiments 1 and 2. This is, of course, hardly surprising because the same stimuli were presented in the same way in all experiments. Again, the difference between the beginrelated and the begin-unrelated conditions was significant at all SOAs $(p<.01)$ except the SOA of $-300 \mathrm{~ms}$.

The results for the end-related and the end-unrelated conditions, however, differed markedly from the results of Experiments 1 and 2 . There was no difference between these conditions at the SOA of $-300 \mathrm{~ms}$ and at the SOA of -150 $\mathrm{ms}$, but at the remaining SOAs the RTs were significantly shorter $(p<.01)$ in the end-related condition than in the endunrelated condition.

In the ANOVA for disyllabic targets, the main effect of IS type and the interaction of IS type and SOA were significant, $F^{\prime}(4,59)=8.78, M S_{\mathrm{e}}=53,543, p<.01$, for the main effect and $F^{\prime}(15,344)=4.08, M S_{e}=18,653, p<.01$, for the interaction. The main effect of SOA was not significant, $F^{\prime}(4$,
$69)=0.49, M S_{e}=128,131$. Analyses of simple effects showed that the effect of IS type was significant at each SOA $(p<$ .01).

Again, the RTs tended to be longer in the presence than in the absence of ISs. At the SOA of $-300 \mathrm{~ms}$ and at the SOA of $-150 \mathrm{~ms}$, the RTs in the begin-related and begin-unrelated conditions differed significantly from the silence condition. At the SOA of $0 \mathrm{~ms}$, these differences and the difference between the end-unrelated and the silence conditions were significant. Finally, at the SOA of $+150 \mathrm{~ms}$, the begin-unrelated, the end-related, and the end-unrelated conditions differed significantly from the silence condition $(p<.05$ for all reported differences).

Planned comparisons of the begin-related and the beginunrelated conditions showed that at the SOA of $-300 \mathrm{~ms}$, the two conditions did not differ significantly from each other. At the SOA of $-150 \mathrm{~ms}$, the difference was significant at the $5 \%$ level of significance and at the following SOAs at the $1 \%$ level. The end-related condition did not differ from the endunrelated condition at the SOA of $-300 \mathrm{~ms}$ or at the SOA of $-150 \mathrm{~ms}$. At the remaining two SOAs, the RTs were significantly faster in the end-related condition than in the endunrelated condition ( $p<.01$ in both cases).

One other finding must be mentioned, namely, that the mean RTs were consistently longer in the begin-unrelated condition than in the end-unrelated condition (see Figure 3). For monosyllabic targets, this difference was significant at all SOAs except the SOA of $+150 \mathrm{~ms}$ (Newman-Keuls tests, $p<$ .05 ). For disyllabic targets, it was significant at the SOA of $-300 \mathrm{~ms}$ and at the SOA of $-150 \mathrm{~ms}$. In the begin- and endunrelated conditions, different sets of ISs were used, which apparently differed in how strongly they interfered with the naming of the target pictures. An inspection of the materials does not suggest any plausible hypothesis concerning the basis 

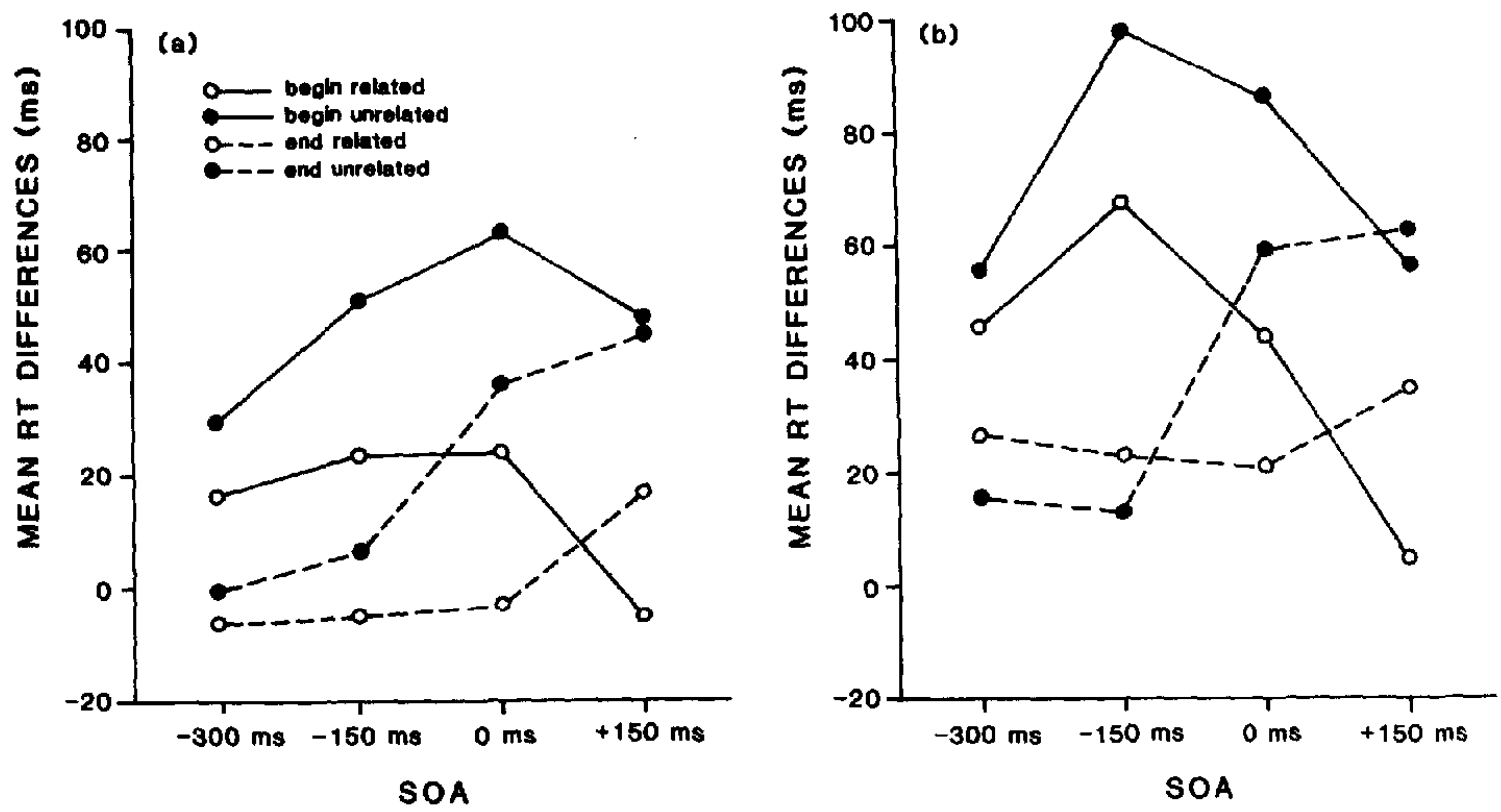

Figure 3. Results of Experiment 3. Mean reaction time (RT) differences (in milliseconds) between the silence condition and the begin-related, begin-unrelated, end-related, and end-unrelated conditions at the SOAs of $-300 \mathrm{~ms},-150 \mathrm{~ms}, 0 \mathrm{~ms}$, and $+150 \mathrm{~ms}$ for (a) monosyllabic targets and (b) disyllabic targets. (Positive values indicate interference relative to the silence condition, and negative values indicate facilitation.)

of this difference. It should be noted, however, that the theoretically important comparisons are those between the begin-related and begin-unrelated conditions and between the end-related and end-unrelated conditions. In the begin-related condition, the same ISs were used as in the begin-unrelated condition, and the same held for the end-related and the endunrelated conditions. Thus, the properties of the ISs that led to the RT differences between the begin-unrelated and endunrelated conditions were controlled for in the comparisons between the unrelated and the corresponding related conditions.

\section{Discussion}

Experiment 3 differed from Experiments 1 and 2 in the timing of the end-related and end-unrelated ISs. In Experiments 1 and 2, SOAs were defined as the time intervals between IS onsets and target onsets. In Experiment 3, they were defined as the time intervals between the onsets of the critical segments included in the ISs and the targets. Thus, in Experiments 1 and 2 the critical segments were presented later in the end-related condition than in the begin-related condition. Moreover, the time period between the onset of the critical segments and the target was the same for all items in the begin-related condition but was variable in the endrelated condition. By contrast, in Experiment 3, the interval between the onset of the critical segments and the target at a given SOA was the same for the begin- and end-related conditions, and it was constant across items.
This change in the timing of the stimuli brought about a marked change in the results for the end-related condition. In Experiments 1 and 2, there were only small facilitatory effects in the end-related conditions in comparison with the endunrelated conditions, which appeared to be independent of the SOA. In Experiment 3, there were no facilitatory effects for either mono- or disyllabic ISs at the SOA of $-300 \mathrm{~ms}$ or the SOA of $-150 \mathrm{~ms}$, but there were strong effects at the SOA of $0 \mathrm{~ms}$ and the SOA of $+150 \mathrm{~ms}$. This difference between the experiments suggests that in Experiments 1 and 2, systematic effects of different SOAs were concealed because of interitem variability in the timing of the critical segments.

In Experiment 3, significant facilitatory effects were obtained in the begin- and end-related conditions. However, the patterns of results for the begin- and end-related conditions and their control conditions were not identical. Consider first the results for disyllabic targets. At the SOA of $-150 \mathrm{~ms}$, we obtained a significant facilitatory effect of $31 \mathrm{~ms}$ in the beginrelated condition (in comparison with the begin-unrelated condition) and a nonsignificant inhibitory effect of $10 \mathrm{~ms}$ in the end-related condition. At the next two SOAs, significant facilitatory effects were observed for the begin- and endrelated conditions. At the SOA of $0 \mathrm{~ms}$, the begin and end effects were equal in strength ( $43 \mathrm{~ms}$ and $38 \mathrm{~ms}$ for the begin and end effects, respectively). At the SOA of $+150 \mathrm{~ms}$, the effect was stronger for the begin- than for the end-related condition (51 ms vs. $28 \mathrm{~ms}$ ), but this difference was not significant, $t(344)=1.07, M S_{\mathrm{c}}=18,653$. The pattern of results for monosyllabic targets was similar. At the SOA of 
$-150 \mathrm{~ms}$, there was again only a significant facilitatory effect of $27 \mathrm{~ms}$ in the begin-related condition; in the end-related condition, there was an insignificant facilitatory effect of 12 ms. The difference between the two effects was not significant, $t(381)<1, M S_{e}=14,092$. At the SOA of $0 \mathrm{~ms}$, significant facilitatory effects of exactly equal strength $(39 \mathrm{~ms})$ were found for the begin- and end-related conditions. Finally, at the SOA of $+150 \mathrm{~ms}$, facilitatory effects of $53 \mathrm{~ms}$ and $28 \mathrm{~ms}$ were obtained for the begin- and end-related conditions, respectively. Both effects were significant, whereas the difference between the effects was not significant, $t(381)=1.63, M S_{\mathrm{e}}=$ 14,092

A possible description of the results is that facilitatory effects were obtained when ISs and targets shared word-initial segments and when they shared word-final segments but that the latter effect was weaker than the former. However, as noted above, the difference between begin- and end-related ISs hardly ever reached significance. Moreover, this description fails to capture an important aspect of the data, namely, that the only SOA for which a significant facilitatory effect was found in the begin-related condition, but not in the endrelated condition, was the SOA of $-150 \mathrm{~ms}$. This held for both mono- and disyllabic targets. Thus, a more specific description of the findings is that there were facilitatory effects in the begin- and end-related conditions but that the effect of related endings began to appear at a later SOA than the effect of related beginnings. As we argue below, this suggests that the phonological encoding of the first syllable of a word begins before the encoding of the second syllable and that the encoding within a syllable also proceeds in a left-to-right manner.

\section{General Discussion}

Three picture-word interference experiments were carried out in which target pictures were presented together with phonologically related or unrelated ISs or were presented alone. In addition, the relative timing of IS and target presentation was varied. Target naming times were longer when ISs were presented than when this was not the case. At certain SOAs, this interference effect was stronger for unrelated than for related ISs. Thus, in comparison with unrelated ISs, phonologically related ones facilitated target naming.

The effects of form-related ISs have been investigated in a number of other picture-word interference experiments (see, e.g., Lupker, 1982; Posnansky \& Rayner, 1977; Rayner \& Posnansky, 1978; and Rayner \& Springer, 1986). In all of these studies, ISs were presented visually. By contrast, in the present study and in an earlier study of our own (Schriefers et al., 1990), auditory IS presentation was used. The results of the two sets of studies presenting ISs in different modalities support two main conclusions. First, form-related ISs differ from unrelated ones in their effects on target naming. Second, the effect of form-related ISs, in comparison with unrelated ones, is facilitatory. By contrast, semantically related ISs tend to have inhibitory effects (e.g., Lupker, 1979, 1982; Rosinski, 1977).

It should be noted, however, that in a related set of experiments by Bock (1987) the production of target words was found to be more difficult after presentation of phonologically related words than after unrelated words. It is not clear why the direction of the phonological effect differed in the two sets of studies. Bock's experiments differ from the picture-word interference experiments reported here in a number of ways, such as in the number of objects that had to be named per trial, in whether the subjects overtly reacted to the ISs, and in the timing of the trials. The effects of these variables should be systematically investigated in future research.

In our experiments, the effects of the ISs crucially depended on the temporal structure of the trials. This has been observed earlier, for instance by Glaser and Düngelhoff (1984), Rayner \& Springer (1986), and Schriefers et al. (1990). The new information gained from the present experiments concerns the microstructure of the trials. Specifically, the effects of phonologically related ISs depended more directly on the timing of the segments that ISs and targets had in common than on the timing of the IS onsets in relation to the target onsets. This finding has obvious implications for the design of future picture-word interference experiments.

The fact that related ISs facilitated target naming at some SOAs but not at others allows for certain conclusions concerning the basis of the facilitatory effect. If, for example, the subjects used the ISs to guess the upcoming targets, the strongest effects should have been observed at long negative SOAs, at which they had ample time to process the ISs. However, the effects were strongest at positive SOAs, and at the longest negative SOA (SOA $=-300 \mathrm{~ms}$ ), the related and unrelated ISs did not differ from each other. On similar grounds, an articulatory account of the facilitatory effect can be ruled out. If the subjects had assumed that the target words would begin with the same sounds as the ISs and had attempted to bring their lips and tongue into an optimal position to produce these sounds as soon as they had heard the ISs, one would also expect to find the strongest facilitatory effect at the longest negative SOAs, at which the subjects had the most time for such articulatory preparation. Thus, explanations of the facilitatory effect that are based entirely on the subjects' strategic use of the ISs are quite implausible. An additional argument against such explanations has already been given above, namely, that identical patterns of results were obtained in Experiments 1 and 2, which differed in the proportions of trials on which related ISs were presented.

An alternative explanation of the facilitatory effect of related ISs is that they speed the selection of the target names from the mental lexicon. Theories of auditory word recognition often assume that as soon as the beginning of a word has been perceived, a cohort of words with that beginning is activated. As more of the word is heard, the set of activated words is reduced more and more, until one word is selected as the word that is actually presented (see, e.g., MarslenWilson \& Zwitserlood, 1989; Zwitserlood, 1989). Thus, when a begin-related IS is presented in a picture-word interference experiment, the target word, which belongs to the same cohort as the IS, is also activated and can therefore be produced faster than in the unrelated condition. This view correctly predicts the facilitatory effect of begin-related ISs. However, the facilitatory effect of end-related ISs cannot be explained because the cohort that is activated when an IS is perceived 
includes only words that begin with the same segments as the IS but not words that end with the same segments.

There are other models of auditory lexical access, such as the TRACE model proposed by Elman and McClelland (1986; McClelland \& Elman, 1986; see also Pisoni \& Luce, 1986), in which the directionality of the mapping between the speech input and mental representations of word forms is less crucial than in the cohort model. Such models might predict facilitatory effects in the begin- and end-related conditions, as in both cases the word forms of the ISs and targets are similar. However, they cannot explain why in Experiment 3 the facilitatory effect in the begin-related condition was observed at an earlier SOA than the effect in the end-related condition, even though the timing of the critical segments relative to the target onset was identical for the two conditions.

The results can, however, readily be explained on the assumptions that phonologically related ISs facilitate the phonological encoding of the target words (i.e., the construction of their word forms) and that the ends of words are encoded later than their beginnings. When an IS is presented, its phonological representation in the mental lexicon is activated and remains active for a certain time period. If some of the segments of the IS are also included in the target, the selection of these target segments will be facilitated, provided that this process takes place soon enough after presentation of the IS. The reason why facilitatory effects were observed for begin-related ISs at the SOA of $-150 \mathrm{~ms}$, the SOA of 0 $\mathrm{ms}$, and the SOA of $+150 \mathrm{~ms}$, but not at the SOA of -300 $\mathrm{ms}$, is that at the earliest SOA the activation of the IS segments had decayed again by the time the phonological encoding of the target began. The reason why, in Experiment 3, the effect of end-related ISs only began to appear at the SOA of $0 \mathrm{~ms}$, whereas the effect of begin-related ISs began at the SOA of $-150 \mathrm{~ms}$, is that the encoding of the ends of the target words began later than the encoding of their beginnings.

The results of the present experiments show that the phonological encoding of the beginning of a word starts before the encoding of its end. It should be noted that they do not imply that the word-initial segments are not active any more when the encoding of the word-final segments is initiated. For example, the encoding of the first syllable of a word is apparently initiated first, and after a certain time period, the second syllable also begins to be activated. The representation of the second syllable is, so to speak, added onto the representation of the first syllable.

In an earlier study, we had used the picture-word interference paradigm to investigate the relative temporal order of the retrieval of meanings and forms of words (Schriefers et al., 1990, Experiment 2). One difference between the results of the two studies should be commented on, namely, the fact that in the present study, facilitation was observed at the SOA of $-150 \mathrm{~ms}$ and at later SOAs for begin-related ISs, whereas in our earlier study the facilitatory effect of begin-related ISs only began to appear at the SOA of $0 \mathrm{~ms}$. End-related ISs were not tested in that study. In both studies, the timing of the phonological effect is crucial for our argument. In Schriefers et al. (1990) we argued on the basis of the absence of a phonological effect and the presence of a semantic effect at the SOA of $-150 \mathrm{~ms}$ for two successive stages of lexical access, namely, a semantic and a phonological stage. In the present study we argue on the basis of the presence of the facilitatory effect of begin-related ISs and the absence of an effect of endrelated ISs at the SOA of $-150 \mathrm{~ms}$ that the phonological encoding of the beginning of a word is initiated before the encoding of the end. It should be noted, however, that neither argument hinges on the absolute timing of the effects. What is crucial is that the semantic effect was observed before the phonological effect and that the effect of begin-related ISs was observed before the effect of end-related ISs.

Nevertheless, the question remains why a facilitatory effect for begin-related ISs was found at the SOA of -150 ms in one experiment and not in the other. The mean RTs for the phonologically related and the unrelated conditions in the study by Schriefers et al. (1990) were identical $(629 \mathrm{~ms})$. The mean RT across mono- and disyllabic response words for the begin-unrelated condition in Experiment 3 of the present study was higher by $16 \mathrm{~ms}(645 \mathrm{~ms})$, whereas the mean RT for the begin-related condition was lower by $12 \mathrm{~ms}(617 \mathrm{~ms})$. RT differences of comparable magnitude were also found between other conditions of the two experiments, such as between the unrelated conditions at the SOA of $0 \mathrm{~ms}(656 \mathrm{~ms}$ vs. $642 \mathrm{~ms}$ ) and the related conditions at the SOA of +150 $\mathrm{ms}(547 \mathrm{~ms}$ vs. $560 \mathrm{~ms}$ ). Thus, the two experiments differed not only in the RTs for the begin-related or begin-unrelated conditions at the SOA of $-150 \mathrm{~ms}$ but also in the RTs for a number of other conditions. We do not know which factors caused these unsystematic differences. The experiments differed in a number of ways. For example, only 9 of the 25 pictures of the present study had also been used in the earlier experiment, and only 3 pictures were combined with the same begin-related ISs in both experiments. In addition, each IS was presented twice in the present study, in combination with different targets, whereas in the earlier study, it only appeared once. To reiterate, it is unclear how the RT differences between the experiments came about. We do not, however, think that they undermine our arguments concerning the relative ordering of different processing steps in lexical access.

At the beginning of this article, two prominent theories of phonological encoding were mentioned, Dell's $(1986,1988)$ and Shattuck-Hufnagel's (1979, 1983). These theories are primarily based on the results of analyses of speech errors, which do not provide evidence on the time course of phonological encoding. Both models assume on grounds of plausibility that successive syllables of a word are encoded sequentially. The present experiments represent one of the few attempts to test this assumption and yield confirming evidence. The models also make certain assumptions about the order of the phonological encoding of the segments within a given syllable. According to Dell's (1986) model, the segments within a syllable are activated in parallel. Shattuck-Hufnagel $(1979,1983)$ and Dell (1988), on the other hand, assume that the segments are selected in sequence, proceeding from the syllable onset to the rhyme. The latter hypothesis is supported by the present data.

If, as our results suggest, the phonological form of a word is created in a number of successive steps, the question of which part of the word form is encoded in each step arises. We can conclude from the present experiments that these 
units must be smaller than entire syllables but, as the beginand end-related ISs for monosyllabic targets both included the nucleus, we have no evidence concerning the nature of the syllable-internal processing units. Results of speech error analyses suggest that these units are likely to be the syllable constituents onset, nucleus, and coda, or the constituents onset and rhyme (see, e.g., Shattuck-Hufnagel, 1979, 1983). Further experiments are planned to distinguish between these hypotheses.

As was mentioned at the beginning of the article, Meyer investigated the time course of phonological encoding in language production in another series of experiments, using a different paradigm (Meyer, 1990, 1991). In the test blocks of those experiments, the subjects either said response words that were related in form or response words that were unrelated in form. The responses were faster in the former than in the latter condition if the response words shared one or more word-initial segments. No facilitatory effect was obtained when the words shared only word-internal or wordfinal segments. These results support the same conclusion as the findings of the present experiments, namely, that word forms are created in a left-to-right manner, both within and between syllables.

However, the findings of the two sets of experiments differ in one important way. In both studies, the production of the targets was facilitated when the critical segments appeared word-initially. In the present experiments, however, we also obtained a facilitatory effect when the critical segments appeared word-finally, provided that they were presented at the right moment. By contrast, in Meyer's experiments, wordfinal critical segments did not facilitate the responses. This is, at first sight, a startling discrepancy.

In Meyer's $(1990,1991)$ experiments, no explicit primes or ISs were presented. Instead, the subjects derived what the critical segments were on the basis of the similarity across the response words. When the response words shared word-initial segments, the subjects probably created and maintained a representation of these segments during the intertrial intervals. When a response word was to be phonologically encoded, its initial segments were still activated and could therefore be selected particularly rapidly. Apparently, the subjects could not prepare in the same way when the words shared wordfinal segments. That is, they could not maintain word-final segments at a high level of activation when they still had to encode the beginnings of the words. Thus, it appears to be possible to create the representation of the first part of a word and append the second part to it but not to first create a representation of the second part of a word and later append the first part to it. Meyer argued that the reason for this asymmetry probably was that in consciously preparing for a word the subjects could not deviate too much from the way they normally encoded words, which she assumed was in a left-to-right fashion. The present results support this hypothesis in that they provide evidence that the encoding of the beginning of a word indeed precedes the encoding of its end.

Still, the question remains why it should be necessary to encode different parts of a word in a particular order. If, as is commonly assumed, segments are inserted into the ordered slots of word or syllable frames, the opposing hypothesis- that segments can be selected in any order-seems much more plausible. As the segments of a word are ordered by association to the ordered slots of a frame, the temporal order in which they reach their destinations should not affect their serial positions in the representation.

An alternative view is that the order of the segments in the phonological representation is not governed by any external principle, such as the order of the slots to which they are associated, but is directly determined by their order of activation. This presupposes, of course, that the order in which the segments of a word are activated is specified in the lexical entry. According to this proposal, the segment that is selected first becomes the first segment of the word, the segment that is selected second becomes the second segment of the word, and so on. This hypothesis correctly predicts that it should not be possible to plan the end of a word before its beginning because the segment that is selected first will by necessity be the beginning of the word.

\section{References}

Bock, J. K. (1987). An effect of the accessibility of word forms on sentence structures. Journal of Memory and Language, 26, 119137.

Boomer, D. S., \& Laver, J. D. M. (1968). Slips of the tongue. British Journal of Disorders of Communication, 3, 2-12.

Browman, C. P. (1978). Tip of the tongue and slip of the ear: Implications for language processing. UCLA Working Papers in Phonetics, 42, 1-149.

Brown, R., \& McNeill, D. (1966). The "tip of the tongue" phenomenon. Journal of Verbal Learning and Verbal Behavior, 5, 325337.

Cowan, N. (1989a). A reply to Miles, Madden, and Jones (1989): Mistakes and other flaws in the challenge to the cross-modal Stroop effect. Perception \& Psychophysics, 45, 82-84.

Cowan, N. (1989b). The reality of cross-modal Stroop effects. Perception \& Psychophysics, 45, 87-88.

Cowan, N., \& Barron, A. (1987). Cross-modal, auditory-visual Stroop interference and possible implications for speech memory. Perception \& Psychophysics, 41, 393-401.

Dell, G. S. (1986). A spreading-activation theory of retrieval in sentence production. Psychological Review, 93, 283-321.

Dell, G. S. (1988). The retrieval of phonological forms in production: Tests of predictions from a connectionist model. Journal of Memory and Language, 27, 124-142.

Dell, G. S., \& Reich, P. A. (1981). Stages in sentence production: An analysis of speech error data. Journal of Verbal Learning and Verbal Behavior, 20, 611-629.

Elman, J. L., \& McClelland, J. L. (1986). Exploiting lawful variability in the speech waveform. In J. S. Perkell \& D. H. Klatt (Eds.), Invariance and variability in speech processes (pp. 360-385). Hillsdale, NJ: Erlbaum.

Fromkin, V. A. (1971). The non-anomalous nature of anomalous utterances. Language, 47, 27-52.

Fromkin, V. A. (1973). Introduction. In V. A. Fromkin (Ed.), Speech errors as linguistic evidence (pp. 11-45). The Hague, The Netherlands: Mouton.

Garrett, M. F. (1975). The analysis of sentence production. In G. H. Bower (Ed.), Psychology of learning and motivation: Vol. 9 (pp. 133-177). San Diego, CA: Academic Press.

Garrett, M. F. (1976). Syntactic processes in sentence production. In R. J. Wales \& E. Walker (Eds.), New approaches to language 
mechanisms. A collection of psycholinguistic studies (pp. 231-255). Amsterdam: North-Holland.

Garrett, M. F. (1988). Processes in language production. In F. J. Newmeyer (Ed.), Linguistics: The Cambridge survey: Vol. III. Biological and psychological aspects of language (pp. 69-96). Cambridge, England: Cambridge University Press.

Glaser, W. R., \& Düngelhoff, F. J. (1984), The time course of pictureword interference. Journal of Experimental Psychology: Human Perception and Performance, 10, 640-654.

Levelt, W. J. M. (1989). Speaking: From intention to articulation. Cambridge, MA: MIT Press.

Levelt, W. J. M., Schriefers, H., Vorberg, D., Meyer, A. S., Pechmann, T., \& Havinga, J. (1991). The time course of lexical access in speech production: A study of picture naming. Psychological Review, 98, 122-142.

Lupker, S. J. (1979). The semantic nature of response competition in the picture-word interference task. Memory \& Cognition, 7, 485495.

Lupker, S. J. (1982). The role of phonetic and orthographic similarity in picture-word interference. Canadian Journal of Psychology, 36, 349-367.

MacKay, D. (1970). Spoonerisms. The structure of errors in the serial order of speech. Neuropsychologica, 8, 323-350.

MacKay, D. (1972). The structure of words and syllables: Evidence from errors in speech. Cognitive Psychology, 3, 210-227.

Marslen-Wilson, W., \& Zwitserlood, P. (1989). Accessing spoken words: The importance of word onsets. Journal of Experimental Psychology: Human Perception and Performance, 15, 576-585.

Martin, N., Weisberg, R. W., \& Saffran, E. M. (1989). Variables influencing the occurrence of naming errors: Implications for a model of lexical retrieval. Journal of Memory and Language, 28, 462-485.

McClelland, J. L., \& Elman, J. L. (1986). The TRACE model of speech perception. Cognitive Psychology, 18, 1-86.

Meyer, A. S. (1990). The time course of phonological encoding in language production: The encoding of successive syllables of a word. Journal of Memory and Language, 29, 524-545.

Meyer, A. S. (1991). The time course of phonological encoding in language production: Phonological encoding inside a syllable. Journal of Memory and Language, 30, 69-89.

Miles, C., \& Jones, D. M. (1989). The fallacy of the cross-modal Stroop effect: A rejoinder to Cowan (1989). Perception \& Psychophysics, 45, 85-86.

Miles, C., Madden, C., \& Jones, D. M. (1989). Cross-modal, auditoryvisual Stroop interference: A reply to Cowan and Barron (1987). Perception \& Psychophysics, 45, 77-81.

Nooteboom, S. G. (1969). The tongue slips into patterns. In A. G. Sciarone, A. J, van Essen, \& A. A. van Raad (Eds.), Nomen: Leyden studies in linguistics and phonetics (pp. 114-132). The Hague, The Netherlands: Mouton.

Pisoni, D. B., \& Luce, P. A. (1986). Speech perception: Research, theory, and the principal issues. In E. C. Schwab \& H. C. Nusbaum (Eds.), Pattern recognition by humans and machines: Vol. I. Speech perception (pp. 1-50). San Diego, CA: Academic Press.
Posnansky, C. J., \& Rayner, K. (1977). Visual-feature and response components in a picture-word interference task with beginning and skilled readers. Joumal of Experimental Child Psychology, 24, 440460.

Rayner, K., \& Posnansky, C. (1978). Stages of processing in word identification. Journal of Experimental Psychology: General, 107, 64-80.

Rayner, K., \& Springer, C. J. (1986). Graphemic and semantic similarity effects in the picture-word interference task. British Journal of Psychology, 77, 207-222.

Rosinski, R. R. (1977). Picture-word interference is semantically based. Child Development, 48, 643-647.

Schriefers, H., \& Meyer, A. S. (1990). Experimental note: Crossmodal, visual-auditory picture-word interference. Bulletin of the Psychonomic Society, 28, 418-420.

Schriefers, H., Meyer, A. S., \& Levelt, W. J. M. (1990). Exploring the time course of lexical access in language production: Picture-word interference studies. Joumal of Memory and Language, 29, 86102.

Seidenberg, M. S., \& Tanenhaus, M. K. (1979). Orthographic effects on rhyme monitoring. Joumal of Experimental Psychology: $\mathrm{Hu}$ man Learning and Memory, 5, 546-554.

Shattuck-Hufnagel, S. (1979). Speech errors as evidence for a serialordering mechanism in sentence production. In W. E. Cooper \& E. C. T. Walker (Eds.), Sentence processing: Psycholinguistic studies presented to Merrill Garrett (pp. 295-342). Hillsdale, NJ: Erlbaum.

Shuttuck-Hufnagel, S. (1983). Sublexical units and suprasegmental structure in speech production planning. In P. F. MacNeilage (Ed.), The production of speech (pp. 109-136). New York: Springer.

Shattuck-Hufnagel, S. (1987). The role of word onset consonants in speech production planning: New evidence from speech error patterns. In E. Keller \& M. Gopnik (Eds.), Motor and sensory processing in language (pp. 17-51). Hillsdale, NJ: Erlbaum.

Stemberger, J. P. (1983). The nature of $/ r /$ and $/ 1 /$ in English: Evidence from speech errors. Joumal of Phonetics, 11, 139-147.

Stemberger, J. P. (1990). Wordshape errors in language production. Cognition, 35, 123-157.

Stroop, J. R. (1935). Studies of interference in serial verbal reactions. Journal of Experimental Psychology, 18, 643-662.

Treiman, R. (1983). The structure of spoken syllables: Evidence from novel word games. Cognition, 15, 49-74.

Treiman, R. (1984). On the status of final consonant clusters in English syllables. Journal of Verbal Learning and Verbal Behavior, 23, 343-356.

Treiman, R. (1986). The division between onsets and rimes in English syllables. Journal of Memory and Language, 25, 476-491.

Underwood, G., \& Briggs, P. (1984). The development of word recognition processes. British Journal of Psychology, 75, 243-255.

Virzi, R. A., \& Egeth, H. E. (1985). Toward a translational model ol Stroop interference. Memory \& Cognition, 13, 304-319.

Winer, J. B. (1971). Statistical principles in experimental design. Nex York: McGraw-Hill.

Zwitserlood, P. (1989). The locus of the effects of sentential-semanti context in spoken-word processing. Cognition, 32, 25-64. 


\section{Appendix}

Materials of Experiments 1-3:

Names of Targets and Related ISs, Followed by Phonetic Transcripts and English Translations

\begin{tabular}{|c|c|c|c|c|c|}
\hline \multirow[b]{2}{*}{ Target } & \multicolumn{2}{|c|}{ Interfering stimuli } & \multirow[b]{2}{*}{ Target } & \multicolumn{2}{|c|}{ Interfering stimuli } \\
\hline & Begin-related & End-related & & Begin-related & End-related \\
\hline hark & hand & bark & bal & ball & dal \\
\hline [hark] & [hant] & [bark] & [bal] & [bat] & [dal] \\
\hline rake & hand & barque & ball & bath & valley \\
\hline klok & klos & mok & vis & vilt & nis \\
\hline [klok] & [klos] & [mok] & [vIs] & [vIlt] & [nls] \\
\hline clock & chock & mug & fish & felt & niche \\
\hline knoop & knook & sloop & bureau & butaan & giro \\
\hline [kno:p] & [kno:k] & [slo:p] & [bu:.'ro:] & [bu:.'ta:n] & ['Xi:.ro:] \\
\hline button & bone & pillow-case & desk & butane & giro \\
\hline veer & veen & peer & geweer & geluid & onweer \\
\hline [ve:r] & [ve:n] & [pe:r] & [X̄a.'we:r] & [Ẍə.'lœyt] & ['on.ve:r] \\
\hline feather & peat & pear & rifle & sound & thunderstorm \\
\hline zak & zang & dak & radio & ratel & medio \\
\hline [zok] & [zan] & [dak] & ['ra:.dI.jo:] & ['ra:.tol] & ['me:.dl.jo:] \\
\hline sack & song & roof & radio & rattle & in the middle of \\
\hline bijl & beits & zeil & sigaar & citroen & bulgaar \\
\hline [beil] & [beits] & [zeil] & [sI.'Ya:r] & [sI.'tru:n] & [bul.'xa:r] \\
\hline axe & stain & sail & cigar & lemon & Bulgarian \\
\hline huis & huid & buis & mantel & manschap & wortel \\
\hline [hceys] & [hoeyt] & [boeys] & ['man.tal] & ['man.sXap] & ['wor.tol] \\
\hline house & skin & tube & coat & crew & root \\
\hline pan & pad & $\operatorname{man}$ & hamer & havik & zomer \\
\hline [pan] & [pat] & [man] & ['ha:.mor] & ['ha:.vIk] & ['zo:.mor] \\
\hline pan & path & $\operatorname{man}$ & hammer & hawk & summer \\
\hline pijl & pijp & mijl & fabriek & fagot & rubriek \\
\hline [peil] & [peip] & [meil] & [fa:.'bri:k] & [fa:.'rot] & [ru:.'bri:k] \\
\hline arrow & pipe & mile & factory & bassoon & column \\
\hline bed & bel & wet & motor & molen & rector \\
\hline [bet] & [bel] & [uet] & ['mo:.tor] & ['mo:.lən] & ['rek.tor] \\
\hline bed & bell & law & motor & mill & rector \\
\hline mond & most & hond & tafel & tapir & luifel \\
\hline [mont] & [most] & [hont] & ['ta:fol] & ['ta:pIr] & ['loy.fal] \\
\hline mouth & must & $\operatorname{dog}$ & table & tapir & porch \\
\hline tang & tak & gang & spijker & spijtig & beker \\
\hline [tap] & [tak] & [Xan] & ['spei.kər] & ['spei.tIx] & ['be:.kar] \\
\hline pliers & branch & passage & nail & regrettable & cup \\
\hline stoel & stoep & doel & & & \\
\hline [stu:l] & [stu:p] & [du:l] & & & \\
\hline chair & sidewalk & goal & & & \\
\hline
\end{tabular}

Note. In the unrelated conditions the same interfering stimuli (ISs) were used as in the corresponding related conditions, but new combinations of ISs and targets were created.

Received December 13, 1990

Revision received March 20, 1991

Accepted March 21, 1991 